\title{
Flexibility and Games in Strategic Investment*
}

\author{
Han T.J. Smit \\ Erasmus University Rotterdam, Netherlands \\ Lenos Trigeorgis \\ University of Cyprus, Cyprus
}

\begin{abstract}
We present a framework for value-based strategic planning combining concepts and tools from strategy and finance. Our 'Expanded NPV' framework reconciles flexibility and strategic commitment, viewing strategic planning as managing a portfolio of real options with competitive interactions. The flexibility and strategic value of a business strategy are interwoven with that strategy's design. We synthesize real options and game theory to evaluate projects or acquisitions. We connect strategic planning and the underlying sources of value creation with the market value of the firm and its three main value components: expected cash flows or assets in place (NPV), flexibility (growth options), and strategic value (moves and games). We develop implications depending on simple or compound growth options, the type and competitive impact of the investment, and relative market power.
\end{abstract}

Keywords: strategic planning, real options, game theory, option games, competition.

\section{Introduction}

The strategic management field has, in the past decade, seen the

\footnotetext{
* This overview article is based on a compilation of ideas from our book Strategic Investment: Real Options and Games, Princeton University Press, Princeton, New Jersey, 2004. We like to thank Robert Merton, Carliss Baldwin, Robert McDonald and Karel Cool for their comments and endorsements on this research. We thank the Association of American Publishers for the 2004 Award for Best Professional/Scholarly Book in Business, Management, and Accounting and the ERIM research institute for the 2005 best book award. The views expressed in this article, and any errors, are of course, our own.
}

(Multinational Finance Journal, 2010, vol. 14, no. 1/2, pp. 125-151)

(C) Multinational Finance Society, a nonprofit corporation. All rights reserved. DOI: $10.17578 / 14-1 / 2-4$ 
development of two fundamental but seemingly contradictory views of strategy. ${ }^{1}$ One view is that strategic flexibility is valuable. As the competitive environment changes quite frequently, flexibility in strategic investment decisions allows firms to optimize their investments and value creation. ${ }^{2}$ This view partly draws on the resource-based view of the firm and the core competence arguments: a firm should invest in those resources and competencies which will give it a distinctive advantage in pursuing or exploiting a set of market opportunities. The other view, based on industrial organization economics and game theory, is that strategic commitment can be valuable. ${ }^{3}$ When a firm commits itself in an irreversible way to an investment or strategic plan, it can influence the strategic actions of its competitors. This creates an opportunity to realize better strategic payoffs and shareholder value.

This article presents a framework for value-based strategic planning that combines features from strategic management theory with modern valuation tools from finance. In the eighties the strategy field has seen a period when finance heavily influenced strategy research. However, this interest gradually ebbed away because it was felt that classic NPV analysis seriously constrained strategy discussions. The 'Expanded

1. See for instance Ghemawat, P., and Del Sol, P. 1998. Commitment versus Flexibility? California Management Review, 40 (4): 26-41.

2. In the strategy literature real options has been used for analyzing technology investments and the ability of the firm to adapt to a changing competitive landscape. See for instance Bowman, E. H., and Hurry, D. 1993. Strategy Through the Option Lens: An Integrated View of Resource Investments and Incremental-Choice Process, Academy of Management Review 18 (4): 760-782; Bettis, R. A., and Hitt, M. A. 1995. The New Competitive Landscape, Strategic Management Journal 16 (Summer): 7-19; McGrath, R. G. 1997. A Real Options Logic for Initiating Technology Positioning Investments, Academy of Management Review 22 (4): 974-996.

3. There is a long literature on timing of investment, preemption and entry. See for instance, Dixit, A. K. 1989. Entry and Exit Decisions under Uncertainty, Journal of Political Economy 97 (3): 620-638; Dixit, A. K. 1979. A Model of Duopoly Suggesting a Theory of Entry Barriers, Bell Journal of Economics 10 (1): 20-32; Dixit, A. K. 1980. The Role of Investment in Entry Deterrence, The Economic Journal 90 (357): 95-106; Pindyck, R. S. 1988. Irreversible Investment, Capacity Choice, and the Value of the Firm, American Economic Review 78 (5): 969-985; Spence, M. 1977. Entry, Capacity, Investment, and Oligopolistic Pricing, Bell Journal of Economics 8 (2): 534-544; Spence, M.1979. Investment Strategy and Growth in a New Market, Bell Journal of Economics 10 (1): 1-19. We refer to the book by Jean Tirole for an overview of strategic aspects of investment behavior in IO. Jean, T. 1990. The Theory of Industrial Organization, The MIT Press, Cambridge, MA. 
NPV' framework discussed here addresses this concern and deals with the new strategic thinking of reconciling flexibility and commitment. It views strategic planning as involving a portfolio of corporate real options actively managed by the firm in the context of competitive interactions.

A key contribution of this article is therefore the integration of concepts and tools from two complementary fields, strategy and finance. Our framework for strategic planning recognizes that future growth opportunity value should explicitly incorporate the impact of volatility, adaptability, and competitive responsiveness. It also recognizes the key role of adaptive resources and capabilities to enable the firm to adjust and re-deploy assets, develop and exploit synergies, and gain competitive advantage via time-to-market and first- or second-mover advantages. It proposes a way of reconciling two practical metrics, the value of assets in place and the value of future growth opportunities incorporated in the stock prices of traded companies. Both components of value can be extracted from financial market data.

\section{Corporate Finance Informs Strategic Planning}

We develop a conceptual framework intended to align the design of an investment strategy with the market value of the firm based on recent developments in corporate finance. We propose to use real options and game theory to evaluate individual projects or acquisitions to shape corporate strategy. An advantage of this approach is that it is consistent with and reinforces the intuitive strategic planning process. The proposed options and games approach to corporate strategy is an attempt to subject managerial intuition about the trade-off between flexibility and commitment to the discipline of a more rigorous analytical process.

Our framework connects strategic planning and the underlying sources of value creation with the market value of the firm and its three main value components. The market value of the firm is not fully captured by the expected cash flows generated by tangible assets that are currently in place (measured by its NPV) and the capabilities to utilize them efficiently. Stock market prices partly reflect a firm's strategic growth option potential as well. ${ }^{4}$ It is precisely the intangible

4. Of course, different stocks generate different earnings streams and have a different 
and strategic value of their growth opportunities that determines most of the market value of high-tech firms in a dynamic environment. This growth option value derives from intangible assets, resources and capabilities to adapt and generate options to undertake or capitalize on future opportunities under the right circumstances. Since growth option value derives primarily from what the firm may invest in the future, rather than from investments it has undertaken in the past, it is particularly sensitive to future competitive moves. In fact, growth option value can be vulnerable not just to the actions of known incumbents, but also to the unanticipated entry of new rivals as new technologies can change drastically the competitive landscape.

The flexibility and strategic value components of a business strategy are interwoven with that strategy's underlying premise and design. Quantitative tools like real options and game theory can be used to complement the strategic thinking process in an interactive way. Of course one must first reason why a particular business strategy leads to value creation. Combining these tools with qualitative insights from strategic management theory can provide a richer understanding of the investment and competitive behavior of firms and the substantial growth and strategic premiums embedded in growth stocks.

Strategic management and corporate finance are seen as complementary for the design and valuation of an investment strategy. To properly link corporate strategy with the value creation process of the firm one needs to first identify the project's main value drivers. These value drivers help provide an interface between the quantitative project valuation methodology and the qualitative strategic planning process that focuses on competitive advantage and the sources of value creation.

\section{An Expanded Valuation Framework}

An important step in bridging the gap between traditional corporate finance theory and strategic planning is the development of an expanded valuation framework that enables a more comprehensive analysis of the relevant value components. Besides the value of expected cash flows from already committed investments, valuation and capital appraisal

growth potential. Growth stocks (e.g., in bio-tech, pharmaceuticals or information technology) typically have high price-earnings and market-to-book ratios. 
methods should properly also capture the flexibility and strategic value components which may contribute significantly to an adaptive firm's market value in an uncertain competitive environment.

Our strategic framework supports a dynamic strategy design and valuation that encompasses NPV analysis and incorporates the dynamic-tree features of real options and game theory when they are relevant. NPV analysis captures the value of management's expected scenario of cash flows, while real options provide an appropriate valuation procedure when future developments are likely to unfold differently than expected. Moreover, when competitors can affect each other's behavior, a broader strategic analysis (often relying on game theory principles) is also called for.

This new valuation approach, based on the combined insights from real options and game theory, is intended to capture the additional flexibility and strategic value beyond the narrow expected cash flow benefits of Net Present Value. It views a firm's growth opportunities as a package of corporate real options that is actively managed by the firm and which may be affected by competitive actions and the introduction of new technologies. If a firm's investment decisions are contingent upon and sensitive to competitors' moves, competitive strategies should be analyzed using a combination of option valuation and game-theoretic industrial organization principles, as the two may interact.

The strategic value of making an early investment commitment to influence competitive behavior in a way that is beneficial to the investing firm must be offset against the flexibility or option value of waiting, and may potentially justify early investment. In our proposed expanded or strategic NPV framework, investment can have two main effects on a firm's value compared to a "wait-and-see" strategy: (i) A flexibility or option-value effect, reflecting the value of management's ability to wait to invest in the business under uncertain conditions, ${ }^{5}$ and (ii) A strategic commitment value effect since early investment may signal a credible commitment that can influence competitors' investment decisions.

In this broader context that incorporates additional flexibility and the strategic considerations of competitive interaction, besides the value of expected cash flows from assets in place and committed plans, business strategy decisions must be based on an expanded NPV criterion

5. Early investment would enhance the commitment value, but sacrifice flexibility value compared to a wait-and-see strategy. 
reflecting total market value:

$$
\begin{aligned}
\text { Expanded (strategic) NPV }= & \text { (passive) NPV }+ \text { Flexibility (option) } \\
& \text { value }+ \text { Strategic value } .
\end{aligned}
$$

This expanded framework allows combining three main value components. Each is discussed in more detail below.

\section{A. (Passive) NPV: Sustaining Competitive Advantage}

To understand the sources of value creation behind a project's positive (expanded) NPV, one must first examine the various value drivers to understand why a particular project is more valuable for this particular company than for its competitors. How firms achieve and sustain competitive advantage that allows earning a return in excess of the opportunity cost of capital is a fundamental question in the field of strategic management. In competitive markets, excess profits attract new entrants or imitation by competitors. Such competitive forces would tend to drive a firm's rate of return down to its cost of capital. In rivalry, excess profits can only exist if the firm has a sustainable competitive advantage that can block pervasive forces of duplication by competitors. $^{6}$

Competitive advantage reflects a firm's ability to perform superior relative to its competitors and eventually results in an excess return over industry profitability. When the advantage can persist over a long period and is resistant to current and potential competitor attempts to imitate, it will result in excess returns and positive (expanded) NPV. The internal resources and capabilities the firm has in its disposal to play the

6. Value creation due to competitive advantage can result from several broad generic strategies, e.g., a cost advantage that allows the firm to produce at lower cost than its competitors or a differentiation advantage that allows the firm to charge a price premium. A cost leadership strategy exploits opportunities that are sources of cost advantage, provided they are not currently exploited by others. For instance, a firm can exploit economies of scale or learning by operating at large quantities while keeping its quality similar to its competitors. A cost leadership position is more likely to be adopted when demand sensitivity to price is highly elastic, more commodity-like and customer services are hard to differentiate. Differentiation can be an important competitive advantage when the firm can create distinctive capabilities and core competences that enable it to charge a price premium. This strategy can be relatively more attractive when price elasticity of demand is low, and when the differentiated nature of products or services allows enhancing its perceived value by customers. 
game in the market shape its strategic position in the industry. A superior strategic position will result in above-average profitability and attract efforts by potential rivals to duplicate the advantage. Sustainable competitive advantage depends on isolating mechanisms in the firm's resource position that can avoid imitation. Firms can make strategic moves such as obtaining first-mover advantages or patents to protect their value creation. But in dynamic market environments, excess profitability can only persist if the firm has gathered together a bundle of capabilities and options to adjust by re-configuring and re-deploying its resources more effectively than its competitors.

\section{B. Flexibility (Options) Value: Adaptive Capabilities}

Where does growth option value come from? To answer this question we must first understand that the internal resources and capabilities of a firm are explicitly linked to environmental opportunities. Firms who use their internal strengths in exploiting environmental opportunities, while moving in a prudent, staged fashion, are more likely to gain competitive advantage. An important question for value creation is: What opportunities exist for dynamically optimizing the use of a firm's resources? A firm's resources are more valuable if they lead to corporate growth options. Tangible resources, such as plant and machinery, may have simple options to expand. But the value of intangible resources, such as patents, critically depends on the generation of future growth options for the firm. Once management knows which of its resources and core capabilities are most important, it can leverage them to enhance competitive advantage.

The intangible value of investments that make up part of the firm's resources derives primarily from the set of options to invest in future growth. Strategic plans often encompass projects which, if measured by cash flows alone, typically appear to have a negative net present value, when in fact they may create a strategic position to invest in valuable follow-on opportunities. An early investment in research and development $(\mathrm{R} \& \mathrm{D})$, for instance, may seem unattractive if its direct measurable cash flows are considered in isolation. Such a strategic $R \& D$ investment should not be seen as a one-time investment at the outset; proper analysis requires explicit consideration of its follow-on commercial and related spin-off applications. In practice firms use strategic investments to enhance their strategic position and appreciate the value of flexibility to react to a dynamic environment. 


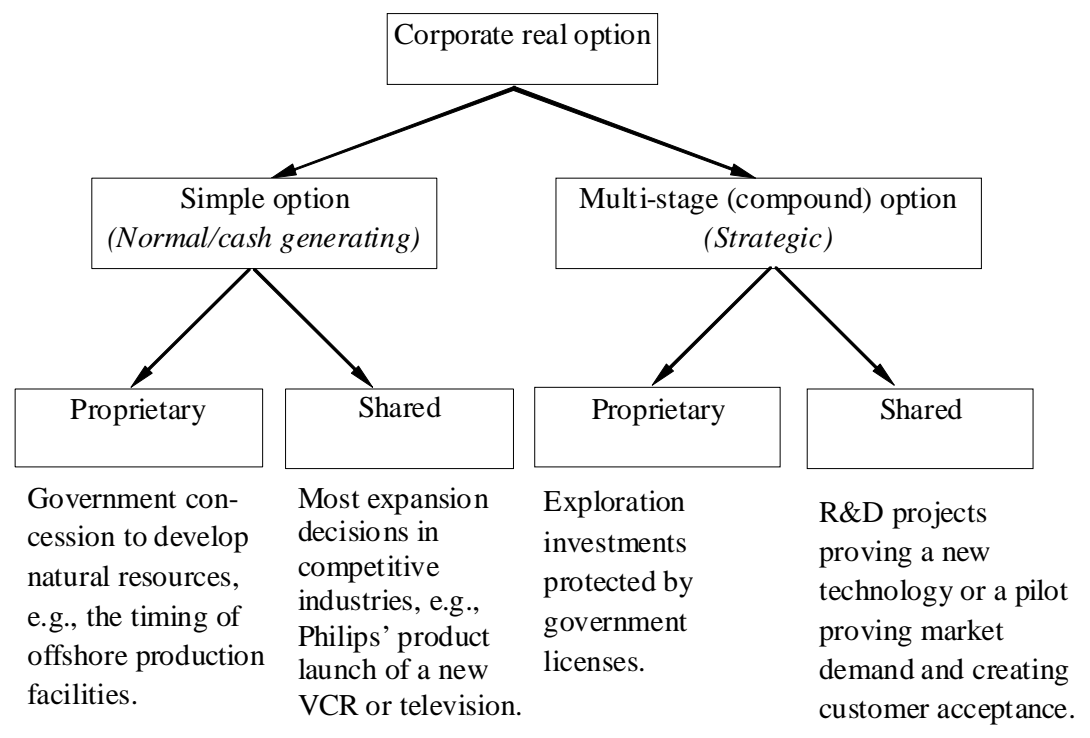

FIGURE 1.- Classification for Corporate Real (Growth) Options

The real options perspective suggests that, as information over the success of a multi-stage investment such as $R \& D$ is revealed, management has valuable flexibility to decide whether to proceed to the next stage, terminate or otherwise alter its future investment plans. An R\&D investment, a pilot project, or entry into a new geographical market have add-on strategic value precisely because they can create or exploit future investment opportunities. Like a call option, the value of the growth options of a firm is influenced by uncertainty, time to maturity, and interest rates.

Thinking of investment opportunities as real options can be facilitated via an option-based classification scheme (see figure 1). The first question managers must ask is, what are the value characteristics of the investment opportunity? Normal investment opportunities that realize their benefits primarily through operating cash inflows are similar to simple options. Compound or multi-stage options, on the other hand, have more strategic value. They should be seen as a first link in a sequence of investment opportunities over time. Strategic investments such as $\mathrm{R} \& \mathrm{D}$, exploration drilling for oil or a pilot project, create valuable follow-on investment opportunities.

Another major aspect affecting the value of a corporate real option 
concerns the corporation's ability to fully appropriate the resulting opportunities for itself or not. Proprietary options can result from license or patent protection. These options represent unique knowledge that cannot be duplicated by competitors, or that exist within a monopoly market structure. Shared options, on the other hand, are those held by more than one competitor in the industry. They include the opportunity to introduce a new product that is not protected from possible introduction of copies, or to penetrate a new geographic market without any barriers of entry by competitors.

A firm's business strategy involves developing and managing an optimal mix or portfolio of such simple (normal) and multi-stage (strategic) investment opportunities. Portfolio approaches that can optimize the bundle of simple and compound growth options can help managers to balance and manage their options portfolio mix. A portfolio approach should consider the balance between direct profitability from commercialization captured by NPV and the value of growth opportunities (PVGO). The mix of simple and compound options in the firm's options portfolio is closely related to the exploration-exploitation activity of the firm. Industries with a high level of innovation in dynamic environments have more compound optional opportunities and higher PVGO-to-price ratios than firms with less R\&D activities.

Growth stocks (e.g., in information technology, pharmaceuticals, or consumer electronics) tend to have a higher growth option value component (PVGO) than income stocks, for two reasons. First, they operate in more volatile and rapidly evolving industries characterized by more frequent technological innovations and a more intensely competitive environment, with the higher underlying volatility being translated into higher (simple) option value. Second, they tend to have a higher mix of compound (multi-stage or growth) options than simple (cash-generating) options, which further levers up their strategic option value (being options on options). This higher (growth) option value, in turn, gets translated into higher market valuations for high-tech or growth stocks that may appear excessive from the perspective of standard DCF valuation methods.

While technological opportunities may vary across industries, adaptive capabilities may be an important source of competitive advantage within industries. Adaptive capabilities reflecting the capacity of organisations to renew their competences and adapt flexibly can be an important source of competitive advantage in an environment characterized by rapid changes. The dynamic capabilities framework of Teece, Pisano and Shuen (1997) emphasizes how organizations first develop firm-specific capabilities and how they renew their 
competences to respond to shifts in their business environment. ${ }^{7}$ Management must develop capabilities to appropriately adapt and reconfigure skills, resources and competences to match the changing requirements of a dynamic environment. Learning and experimentation can help identify new production opportunities. This requires constant surveillance of markets and technologies for various types of opportunities that enable management to adapt more efficiently. The ability to effectuate necessary adjustments requires scanning the environment, evaluating markets and competitors, and quickly accomplishing reconfiguration and transformation ahead of competition.

From a real options and dynamic capabilities perspective, where the firm is going in the future depends both on the historical path it has traveled, the technological opportunities that lie ahead and management's dynamic strategic plans. As soon as management starts down a path, it is faced with uncertainty about developments in the industry and competitive moves, and it needs to respond flexibly to these developments. As we begin to think in options terms, each project in a strategic investment program can be seen as a necessary link in generating follow-on options to invest, or as part of a bundle of corporate options and competences that extends over the long term. These options and competences may lose their value if they no longer matter in the marketplace or if they can be readily replicated by competitors. ${ }^{8}$ Management should not treat the trajectory and pattern of related outlays along a strategic path as a static scenario, but instead dynamically adjust it depending on uncertain developments in the business environment. A firm engaged in R\&D may find the path ahead closed off, though break-throughs in related areas may still become attractive. Likewise, if the path ahead is extremely attractive, there may be no incentive for a firm to shift the allocation of resources away from its traditional pursuits.

A competence-building strategy is "history" dependent. The chosen path today does not only define which investment alternatives are open to the firm today, but it also constrains its choices in the future. Path dependencies arise when investment choices are costly to reverse and affect the value of future investment alternatives. Path dependencies limit options for switching along various strategic paths.

7. Teece, D. J.; Pisano, G.; and Shuen, A. 1997. Dynamic Capabilities and Strategic Management, Strategic Management Journal, 18 (7): 509-534.

8. On the other hand, cooperation in R\&D and coordination of a product standard among competitors may potentially increase the total economic pie for the industry. 


\section{Strategic Value: Moves and Games}

Game theory, sometimes referred to as strategic conflict in the strategic management literature, analyzes strategic moves and the nature of competitive interaction between firms. ${ }^{9}$ Companies make strategic moves to influence a rival's behavior in an advantageous way. Examples of strategic moves include an early irreversible investment, a threat of a price war or law suit, a promise to cooperate, or an announcement of a path-breaking discovery. ${ }^{10}$

Similar to other mechanisms used to protect the profitability of an industry against potential entrants, like high entry or exit barriers, firms make strategic moves to protect their competitive advantage against erosion or duplication from existing competitors. A firm can use a deterrence strategy of signaling retaliation actions or can adopt an early-mover strategy to exploit pre-empting advantages. Early-mover advantages in the competitive exercise of real options are important "isolating mechanisms" avoiding duplication by competitors. There are also potential interactions among the value components. The commitment effect of an early mover advantage may help sustain a competitive advantage from assets in place (NPV) or help appropriate growth option value.

With first-mover advantages, pre-commitment can be used to influence competitive behavior to a firm's advantage, e.g., by increasing the acquisition cost or reducing user revenues for competitors with a weaker position. Consider an early mover that invests aggressively in large-scale production facilities in a market with economies of scale. Investment in excess production capacity here serves as a credible commitment. Later entrants would face less valuable expansion opportunities as they would expand with a reduced scale to avoid a market-share battle. By making it more difficult for others to catch up, an early investment commitment can lead to higher profits for the early-moving firm. Similarly, first-mover advantages can be gained with

9. A game describes a strategic context where decisions of firms are interdependent. This can be a zero-sum game, involving the division of a given economic pie, as well as cooperation or mutual benefit decisions that can enhance total value. In the first case, the gain of one firm is the other firm's loss. For instance, in electronics or pharmaceuticals firms enter into patent races to improve their competitive position and their ability to appropriate the growth opportunities in the industry at the expense of their rivals.

10. A move will have little effect or credibility if it can be costlessly undone. To be effective, such strategic moves must involve irreversible or costly commitments. 
proprietary technological leads, experience curve effects, customer loyalty with buyer switching costs, network externalities, reputation and buyer choice under uncertainty.

Although an early investment commitment would kill the option value to "wait-and-see" and potentially invest later, it can make the firm better off from a strategic perspective. Lack of flexibility to retreat from the market may alter a competitor's beliefs about the intensity of potential competition and the future profitability in the market. Inflexibility or "burning one's bridges" may signal commitment to pursue the chosen strategy to the very end. If a competitor is forced to react in a desired way this inflexibility has significant commitment value.

In some cases there may be early-mover disadvantages (or late-mover advantages). For instance, in cases where the benefits of the strategic investment are shared, later movers may free-ride on a pioneering firm's investment. This may be the case in $R \& D$, some types of infrastructure investments, and buyer education. In addition to the ability to free-ride on an early-mover investment, late movers may benefit from the resolution of technological and market uncertainty or from technological discontinuities that open up new technology options. The option value to wait is important when uncertainty is high and there is benefit from waiting to exercise investments as uncertainty gets resolved. Early-movers may risk failure to establish a sustainable competitive advantage because they may bet on the wrong technology when there is substantial uncertainty about the future product standard. On the other hand, early entry might be attractive in cases where the firm can influence the way this uncertainty gets resolved.

Game theory coupled with real options valuation can yield powerful insights in these strategic situations. The combined framework described here provides a dynamic view of business strategy to assist practitioners in the building of long-run competitive advantage and strategic adaptability.

\section{Strategic Planning, Option Games Interaction and Impact on Market Value}

Value creation suggests that managers should focus their investment strategy on the relevant value drivers that affects both assets in place as well as growth options. In fact, they should target and reflect to 
optimally manage dynamically the project mix between assets in place and growth options, as this will ultimately affect the firms. ${ }^{11}$ Growth options turn into assets in place as they are optimally exercised over time. Table 1 summarizes the relevant value drivers, strategy, growth options and strategic moves that can help build a strategic position. Columns 1 and 2 in table 1 relate a value-creating strategy to opportunities or market imperfections in the external environment. For instance, in one market a market-leader strategy might be successful because of economies of scale, while in another strategy might be a success due to product differentiation and technological innovation. Each strategy encompasses a set of operational and strategy decisions in addition to investment in resources. A cost-leader strategy, for example, utilizes a low price policy to enable the firm to quickly expand market share, construction in facilities of efficient scale, and investment in cost-reducing production.

Firms naturally scan the external environment for resources which fit well with the assets and capabilities they already have in place and for which they are likely to face less competition. Proper strategy design thus requires careful consideration of strategic investments that can build competitive advantage and allow leveraging follow-on commercial projects. Multi-stage (compound) options have more strategic value in that they enhance subsequent commercial option value. The benefits of later commercialization that may be made possible by an early strategic investment must be properly captured by determining the option value of the overall strategy. Each project in a strategic investment program can be viewed as a link in creating future commercial opportunities, and should therefore be analyzed with option valuation techniques. Compound options, such as $R \& D$, pilot projects in a new market, or up-front goodwill investments, create a resource barrier that provides defense against potential entrants. Patents, proprietary technologies, or know-how, reputation or brand-name equity capital serve to protect, enhance or leverage the value of commercialization options. The more proprietary the strategic benefits of a growth option, the more the option enhances competitive advantage and the more valuable the overall strategy will be.

In designing and valuing a strategic investment program, management must be careful to recognize competitive interactions.

11. Berk, J. B.; Green, R. C.; and Naik, V. 1999. Optimal Investment, Growth Options, and Security Returns, Journal of Finance 54: 1553-1607. 


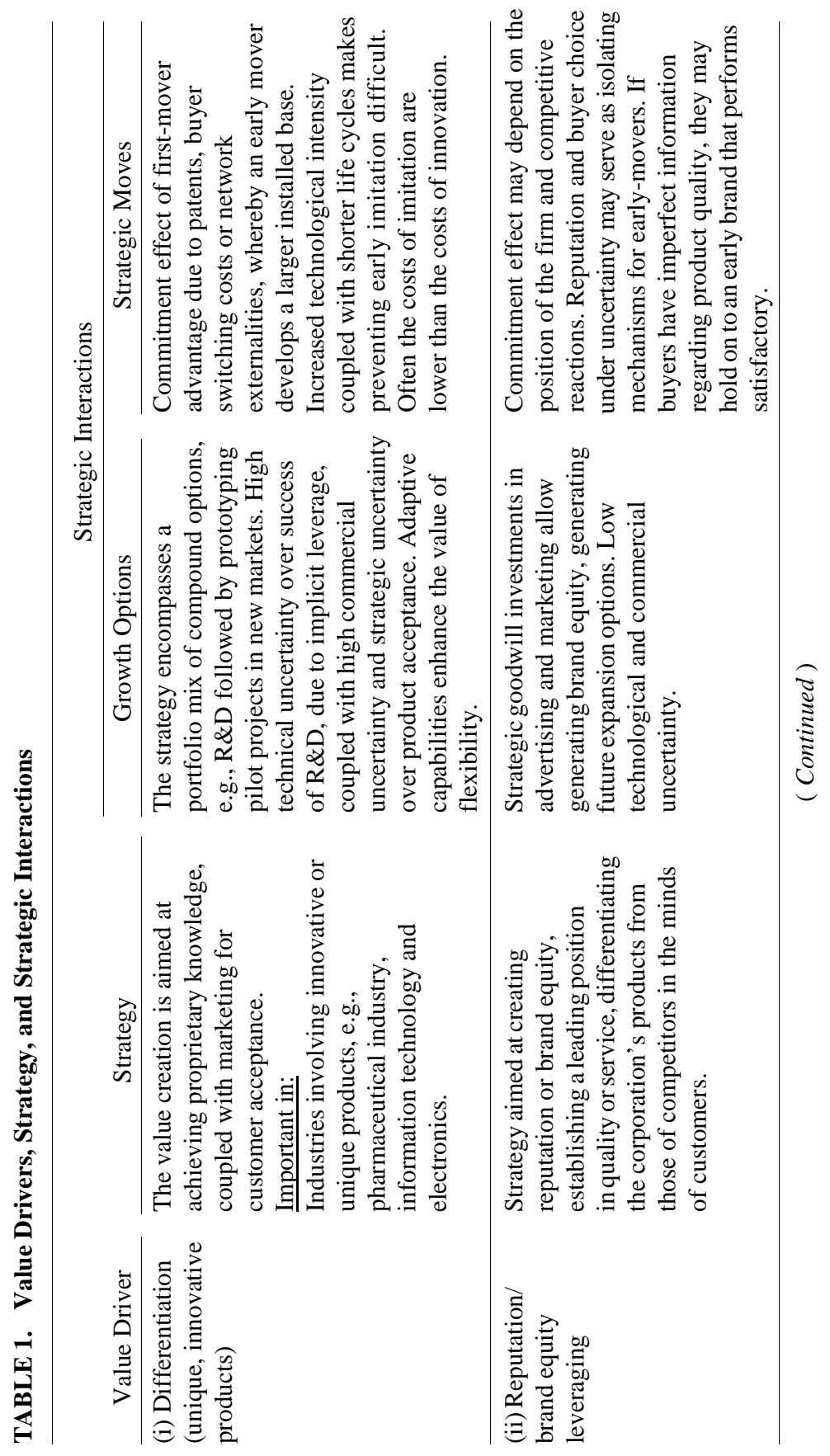




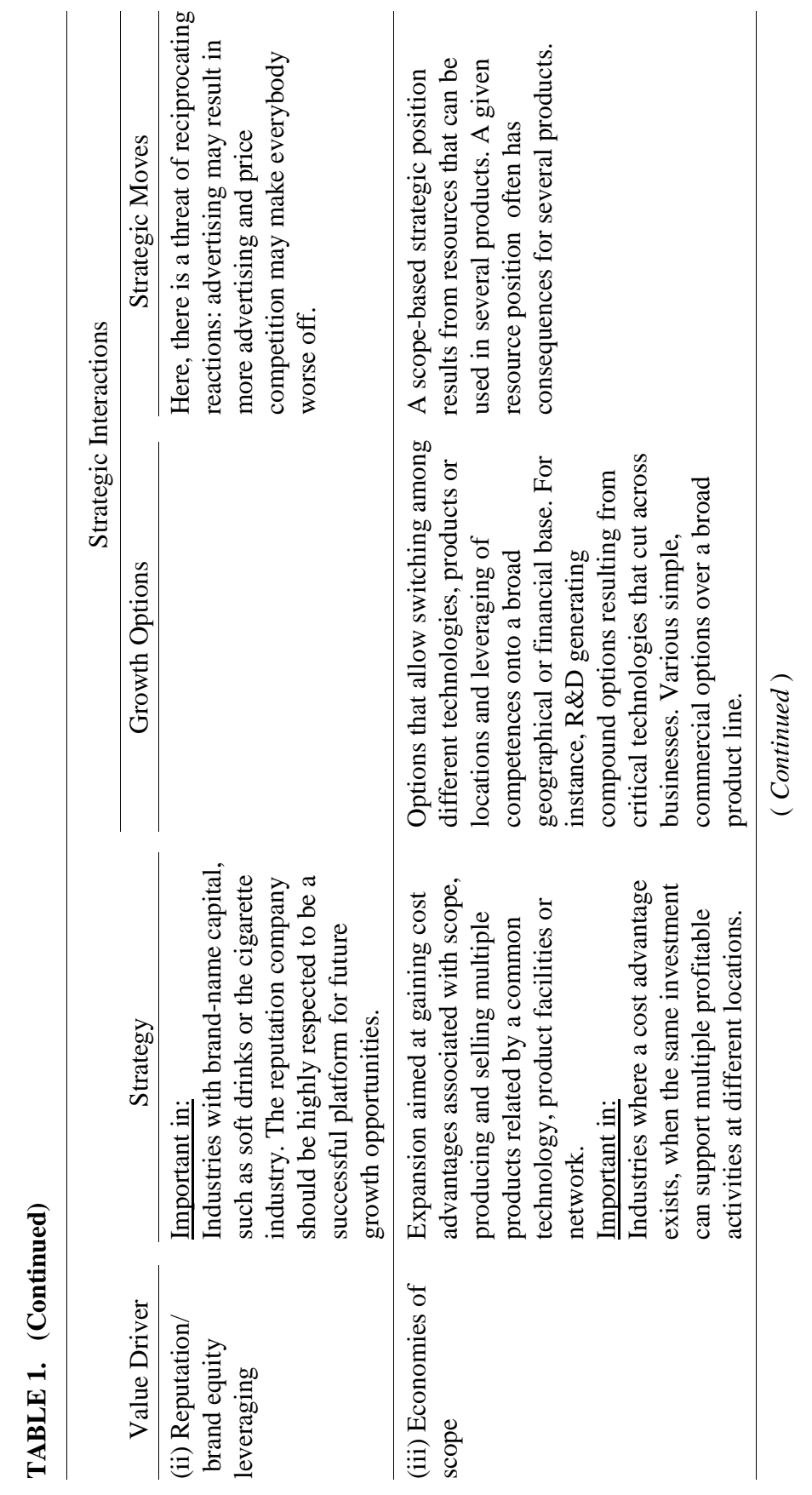


140

Multinational Finance Journal

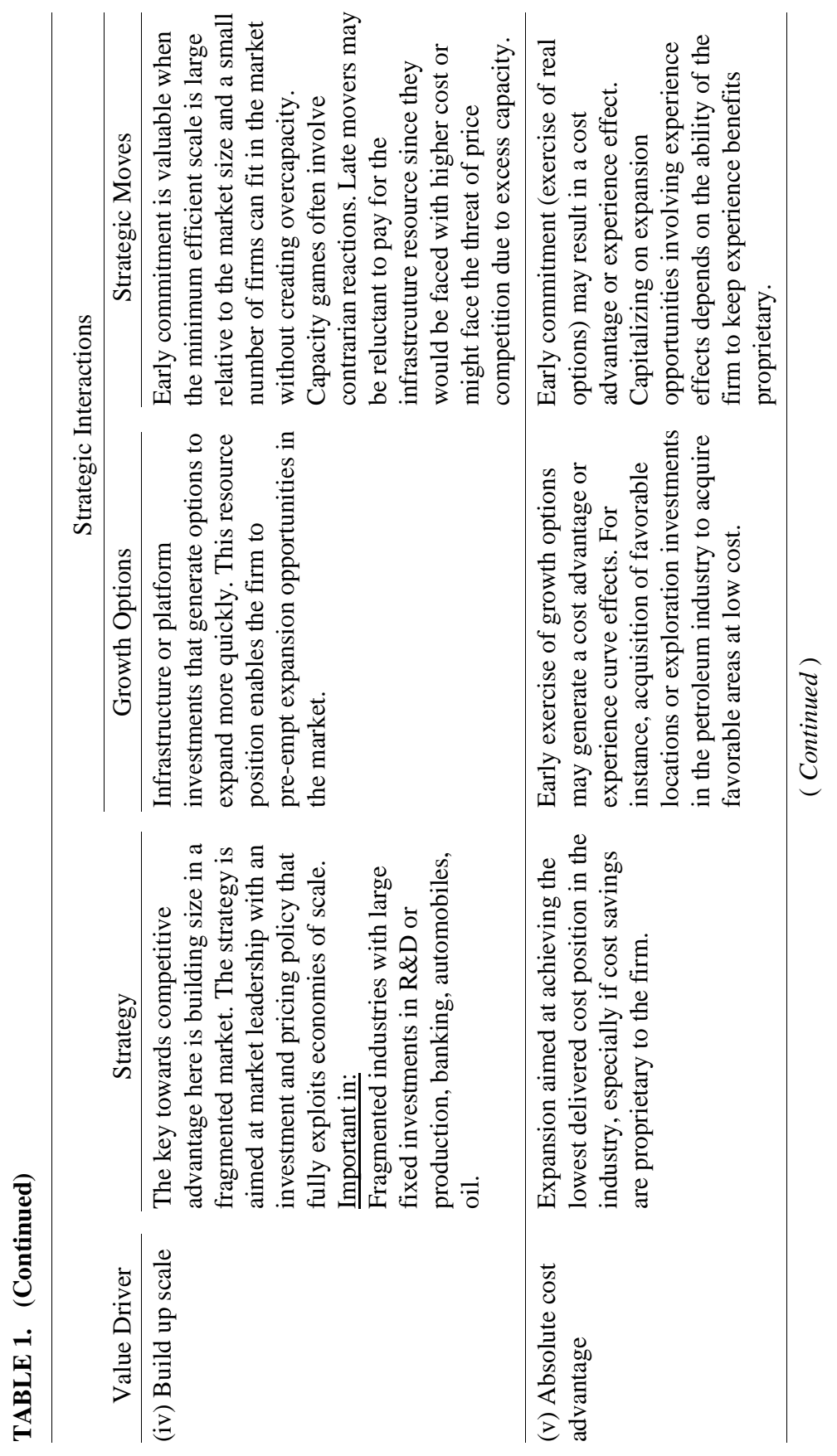




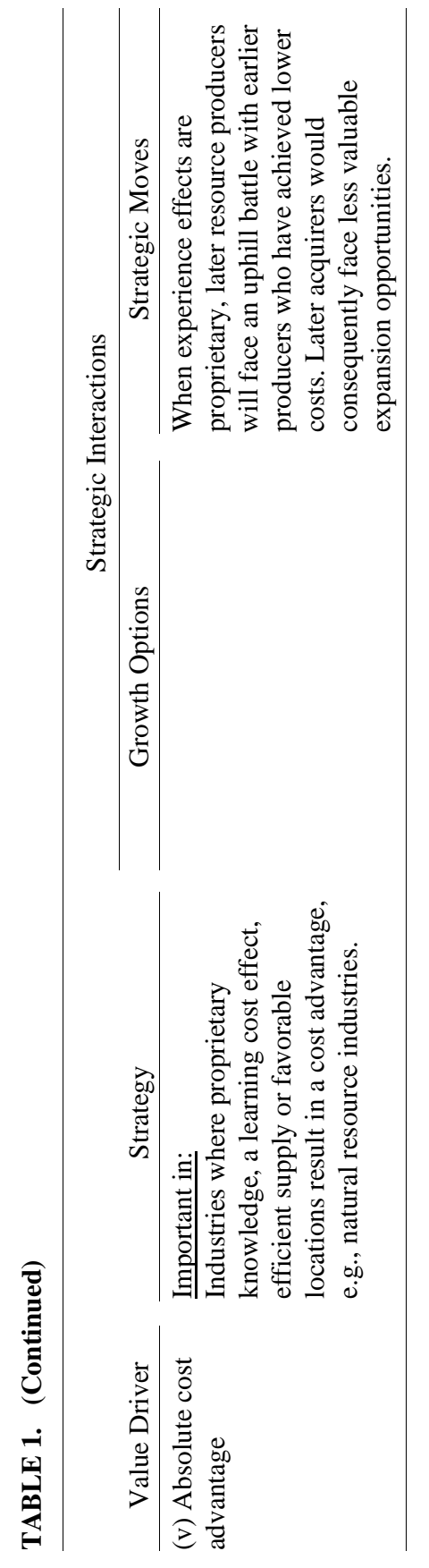


When the benefits of a pioneer's growth options are proprietary, later entrants would expect lower value for their own expansion opportunities. But when the benefits are shared, strategic uncertainty may also reduce the costs of later entrants. Innovative investments are critically dependent on the ability of the innovative firm to appropriate the resulting benefits. When benefits are proprietary, a technological lead will enable a firm to better capitalize on valuable follow-on options in a later-stage exercise game. It may also enable the firm to motivate and retain better people. When the results are shared or can be easily replicated by followers, imitation may be easier than invention.

\section{Implications of the Option Games Framework}

The proposed expanded NPV framework can capture both the strategic commitment value of competitive initiatives or reactions, as well as the flexibility value of altering planned investments in pursuing a business strategy under uncertainty. By contrast to the flexibility value implicit in a "wait-and-see" or staged approach, early irreversible investment may entail commitment value if it informs competitors about the future profitability of their options in a given market. We develop several implications of our framework depending on the simple or compound nature of the firm's options, the type and competitive impact of the investment, and the strategic context of the market.

\section{A. Investment Timing Games for Simple Options}

As entry barriers and the number of competing firms can determine the intensity of competition and market power in an industry, competitive moves can influence the value and timing of commercial projects. A deferrable project in a monopoly situation can be seen as an exclusive investment opportunity that can benefit from a wait-and-see strategy. On the other hand, postponement of a shared option in a fragmented competitive market implies a potential loss in expected value of the project due to anticipated entry by competitors. In the absence of a structural competitive advantage it may sometimes be justified to invest early to preclude this erosion of value.

An oligopoly situation lies in between. When a few firms with individual market power are competing in the industry, a firm's investment decisions are made with the explicit recognition that they 


\begin{tabular}{|c|c|c|}
\hline & $\begin{array}{l}\text { NPV FROM } \\
\text { INVE }\end{array}$ & $\begin{array}{l}\text { IMMEDIATE } \\
\text { TMENT }\end{array}$ \\
\hline & Low & High \\
\hline MARKET POSITION & $\begin{array}{l}\text { Low commitment value } \\
\text { and high flexibility value } \\
\text { enhances postponement. } \\
\text { No threat of preemption }\end{array}$ & $\begin{array}{l}\text { High commitment value and II } \\
\text { low flexibility value enhances early } \\
\text { invest ment. } \\
\text { No threat of preemption, } \\
\text { dominant position increases the } \\
\text { ability to expand market share. }\end{array}$ \\
\hline Weak & $\begin{array}{l}\text { LowNPV value supports } \\
\text { deferment until the market } \\
\text { develops sufficiently } \\
\text { for the firm to enter. } \\
\text { Threat of preemption. }\end{array}$ & $\begin{array}{l}\text { Early investment to capt ure IV } \\
\text { high NPV and preclude erosion of } \\
\text { value. } \\
\text { Risk of preemption in which case } \\
\text { NPVmight become negative. }\end{array}$ \\
\hline
\end{tabular}

FIGURE 2.- Timing Strategies of Follow-on Investments under Competition

may invite competitive reaction, which in turn impacts the value of the investment opportunity. In a duopoly, a prisoners' dilemma situation can occur in which the competitive pressure of the other firm investing first and winning the innovation race induces both firms to invest prematurely. Instead, it would have been better for the two firms to defer investment in case of low project value and uncertain market demand. If the firms can (implicitly) coordinate their investment, they may find it preferable to postpone to jointly optimize against demand uncertainty.

If the competitors' market power differs, we can distinguish among different investment timing strategies. ${ }^{12}$ When early-mover advantages are present, timing strategy is based on the firm's strength in relation to its competitors. A competitor with a stronger resource position would likely have more valuable options. Pre-emptive exercise of its options can affect the acquisition cost (exercise price) or the user revenues (underlying value) for weaker competitors. If the firm is able to use an early-mover advantage in its favour, it can create a situation where it becomes increasingly difficult for others to catch up. The value erosion for late-movers will be greater if the market power of the leader is

12. Smit H. T. J., and Ankum, P. A. 1993. A Real Options and Game-Theoretic Approach to Corporate Investment Strategy under Competition, Financial Management 22 (3): 241-250. 


\section{COMPETITION}

\begin{tabular}{|c|c|c|}
\hline & $\begin{array}{l}\text { Contrarian } \\
\text { (down-sloping reaction/ } \\
\text { substitutes) } \\
\text { e.g., quantity competition }\end{array}$ & $\begin{array}{l}\text { Reciprocating } \\
\text { (up-sloping reaction/ } \\
\text { complements) } \\
\text { e.g., price competition }\end{array}$ \\
\hline $\begin{array}{l}\text { Tough position } \\
\text { e.g., proprietary investment } \\
\text { (hurt competition) }\end{array}$ & $\begin{array}{l}\text { I } \\
\text { commiting and offensive } \\
\text { Invest (+ strategic effect) }\end{array}$ & $\begin{array}{l}\text { III } \\
\text { flexible and inoffensive } \\
\text { Don't invest/ wait (- strategic effect) }\end{array}$ \\
\hline $\begin{array}{l}\text { Accommodating } \\
\text { e.g., shared investment } \\
\text { (benefit competition) }\end{array}$ & $\begin{array}{l}\text { flexible and offensive } \\
\text { Don't invest/ wait (- strategic effect) }\end{array}$ & $\begin{array}{l}\text { IV } \\
\text { commiting and inoffensive } \\
\text { Invest (+ strategic effect) }\end{array}$ \\
\hline
\end{tabular}

FIGURE 3.- Sign of the Strategic Effect and Competitive Strategies Following a Tough or Accommodating Position under Contrarian or Reciprocating Competition

higher, because an early investment on its part will take away a large market share. A firm with substantial market power can sometimes pre-empt a competitor. Projects with low net present value from immediate exercise are more likely to be postponed. Low project value by weaker companies makes them vulnerable to pre-emption by a stronger competitor with high project value.

Based on the strength of a firm in relation to its competitors (dominant or weak) and the value of the project in relation to the risk of pre-emption, one can develop simple option investment strategies as illustrated in figure 3 .

(I) Projects that have relatively small net present value (NPV) from immediate investment and relatively larger flexibility value in uncertain markets are better candidates to be postponed. If a company has a dominant market position in its industry, there is little threat of complete pre-emption by a weaker competitor. The firm can safely postpone the project and decide to invest later if the market develops favorably or if the weaker competitor invests first, especially if it can prove the market without gaining a significant market share. 
(II) Projects with relatively high NPVs in relation to the risk of pre-emption and less flexibility value are less likely to be postponed. There may be a high opportunity cost from deferment in the form of lost operating cash flows during the deferment period, inducing a dominant company to invest early.

(III) If the company has a weak position in the market, the project will not likely have a large NPV up-front. Only later, if the market develops sufficiently, will it make sense to initiate the project.

(IV) If the company has a weak market position but its particular project nonetheless appears to have a positive NPV, it should invest immediately if it can pre-empt competitors or create a cost advantage. However, because of its weak position, there is a risk that a stronger competitor can come in subsequently and erode its NPV, even turn it negative ex-post.

In general, the company will tend to postpone commercial projects when net present value is low and market demand is uncertain. The degree of non-exclusiveness of the investment opportunity also influences the investment strategy. When there are many competitors, each with negligible market power, their entry can erode some of the value of the project and can be treated as exogeneous. When there are few competitors with great individual market power, however, competitive interaction must be considered through option games and sometimes there can be a threat of complete pre-emption.

\section{B. Investment Games Involving Strategic Options}

Considerer a sequence of investment decisions by a pioneer firm in which a first-stage strategic (e.g., R\&D) investment commitment influences its relative cost position vis-à-vis its competitor in the commercialisation stage and the subsequent cash-generating investment decisions by either competitor. The trade-off between flexibility and the strategic commitment value of the first-stage $R \& D$ investment may interact with market structure by altering the competitor's equilibrium quantity or changing the market structure altogether.

An early strategic investment would reduce option or flexibility value, other things constant, but it can have a high or low (even negative) net commitment value, depending on the strategic effects. A 
key factor in determining the commitment value and an appropriate competitive strategy is whether an early strategic commitment makes the pioneer firm more "tough" (i.e., whether it can appropriate the resulting benefits and hurt its competitors), or "accommodating" (i.e., whether the resulting advantage can be shared with and benefit its rivals) in the commercialization phase. A second factor is whether competitive reactions are reciprocating or contrarian, i.e., whether the competitors' reactions are similar or whether they are opposite.

Often quantity-type competition, when a larger quantity produced by one firm (e.g., capturing a larger market share via economies of scale or a learning-cost advantage) results in a lower quantity for its competitor in equilibrium, is regarded as contrarian. Competitive reactions are typically reciprocating (or complementary) under price competition. Here, a low price setting by one firm is expected to be matched by a low price by the competing firm, resulting in lower profit margins for both. Such price wars have often been disastrous in the food, tobacco and airline industries. In such situations, firms may be better off if the leading firm sets a higher price instead that competitors would follow, allowing implicit coordination benefits. Box Insert Illustration 1 provides an example of reciprocating price competition and retaliation in the cigarette industry. (See appendix A)

In some cases, an early investment commitment can be a strategic disadvantage if it reduces the firm's ability to respond toward aggressive competitors who can exploit shared benefits from the strategic investment, or if it provokes a retaliating competitive response and intense rivalry. Based on a combination of real options valuation with basic game-theory principles from industrial organization, we distinguish various competitive investment strategies depending on whether competitive actions are reciprocating or contrarian, and whether the resulting benefits are proprietary (tough) or shared (accommodating):

(I) When competitive actions are contrarian and the benefits of strategic investment can be appropriated by the pioneering firm at the expense of its competition, the firm should commit to an offensive strategy and invest early. Strategic commitment makes the firm tougher in the commercialization stage by creating a proprietary advantage when investing in follow-on projects. If competitive actions (e.g., quantities) are contrarian, competition will retreat in the commercial stage and the pioneering firm can become a leader as demand grows. 
(II) When the benefits of strategic investment are shared and contrarian competition would respond aggressively, the firm should not invest immediately but rather follow a flexible but offensive strategy. By delaying strategic investment, it prevents its competition from exploiting the resulting shared benefits to grow at its own expense.

(III) When the benefits of strategic investment can be appropriated by the firm at the expense of competition, and competition may reciprocate with an aggressive response, the firm should follow a flexible and inoffensive strategy. The firm should avoid committing to the strategic project to preserve its resources and flexibility and avoid intensified price competition in the later stage of the market.

(IV) When the strategic investment benefits both firms and competition would reciprocate with an accommodating position (e.g., maintaining high industry prices), the pioneer should follow a committing but inoffensive strategy. It may invest in goodwill in an inoffensive way, avoiding intense price competition that would hurt the industry. Through maintaining higher prices, both firms may enjoy more profitable follow-on commercial options.

The above analysis of competitive strategies can be extended to incorporate the impact of additional factors, such as uncertainty in market demand and a stochastic outcome of the R\&D effort, incomplete or asymmetric information, $R \& D$ competition versus cooperation in a joint research venture, and learning or experience cost effects. We next discuss implications of our proposed framework. (See appendix B)

\section{Implications For Strategic Analysis}

In the new dynamic competitive landscape that high tech and other industries are facing today, it becomes essential for firms to be more flexible in their investment programs, allowing management to change the amount, rate, timing or scale of investment in response to new, unexpected developments and competitive moves. The above framework marrying real options valuation with game-theoretic industrial organization principles enables a proper accounting of interdependencies among the early strategic commitment and sequential follow-on decisions in a competitive interactive setting. This article 
advocated an expanded NPV decision rule and valuation process for analyzing various competitive strategies by integrating real options with basic principles from game-theoretic industrial organization and strategic management.

Implementing the integrated games and options methodology and estimating the boundaries of key input parameters is subject to some limitations. ${ }^{13}$ As with any approach, the valuation results are sensitive to hard-to-estimate parameters such as investment outlays in future opportunities and the level of technical and demand uncertainty. Option parameters (e.g., exercise price, firm-specific volatility or option maturity) in practical applications are likely to be idiosyncratic for each firm. For instance, the exercise cost or exercise capacity of a firm may depend on what other organizational assets and resources the firm has accumulated. The value of the underlying cash flows (V) is also likely to be idiosyncratic, as some firms may earn a premium because of reputation or other effects. The uncertainty each firm faces is likely to be idiosyncratic as well. Higher firm-specific uncertainty increases the value of the firm's growth options, increasing its incentive for waiting in the trade-off between strategic commitment and flexibility. Furthermore, beyond the technical uncertainty of the innovative (R\&D) process, organizational and strategic uncertainties may also be subject to influence. To have more confidence in the numbers, strategic planning and numerical valuation should complement each other. Given the diversity of investment problems, the options-and-games framework can provide a guide for evaluating investment alternatives. Obviously the model needs to be tailored to specific organizations.

The real options-and-games approach to evaluating competitive strategies is an attempt to subject strategic intuition to the discipline of a more rigorous analytical process. The combined framework can help guide managerial judgment in deciding whether and when it is appropriate to grow locally or globally, and when participation in a network or a strategic alliance is the preferred route. We believe that simplified versions of the options-and-games framework will gradually

13. Any quantitative valuation attempt involving competitive games should be taken with caution as it is typically predicated on assumptions about predicted rational behavior on the part of competitors that may not fully represent practical reality. A promising avenue where games may require little rationality and players may reach equilibrium by communicating, adapting, or evolving rather than calculating the equilibrium is discussed in Camerer (1991). New developments in game theory in combination with option theory can make the analysis more dynamic. See Camerer, C. F. 1991. Does Strategy Research Need Game Theory? Strategic Management Journal 12 (Winter): 137-152. 
find their practical implementation in many key domains, such as the valuation of joint research ventures, alliances or platform acquisitions.

In order to enable this approach as a practical aid to corporate planners, it is useful to develop appropriate user-friendly software with simulation capabilities. For normative kinds of applications, a discrete-time binomial analysis maybe the most suitable approach. It preserves important features such as modularity to embed the many strategic features necessary for a realistic setting, tractability of the paths in the model, and incorporating potentially multiple underlying stochastic asset processes (under Brownian motion, mean reversion etc). In addition, it may accommodate an exogenous chance of competitive entry, obsolescence or catastrophic shocks.

Given the increasing attention paid by corporations to option-pricing application and implementation issues, the practical use of real option analysis looks quite promising. Real options concepts and tools have been considered by leading firms in natural resources, pharmaceuticals, telecommunications, consumer electronics and subsequently are being considered in most business areas.

Accepted by: Prof. P. Theodossiou, Editor-in-Chief, March 2009

\section{Appendix}

\section{A. Box Insert Illustration 1: Reciprocating Price Competition and Retaliation in the Cigarette Industry}

The US cigarette industry is a good example of retaliatory behavior via advertising and price competition. The cigarette industry is an oligopolistic market characterized by reciprocating competitive reactions. Advertising expenditures are used to differentiate a firm's products to gain market share. This often invites a retaliating tough campaign from rivals, forcing firms to invest more heavily in advertising.

The accompanying figure shows the stock price performance of several cigarette producers. When dominant firms such as RJR Nabisco and Philip Morris, announce their intention to raise their prices, it seems the other cigarette producers follow within days. The dominant firms' response seems soft or accommodating towards the rivals. Most of the time this industry exhibits coordination in prices, which makes firms in 
this industry highly profitable. However, from 93 -95 the decision of one player to go after this discount niche-market invited a retaliating reaction by the larger competitors. In a reciprocating tit-for-tat fashion the large competitors introduced their own lines of discount cigarettes Following this temporary price war the coordination in cigarette prices was subsequently restored. In the subsequent period the cigarette industry faced legal challenges that led to decline in stock prices.

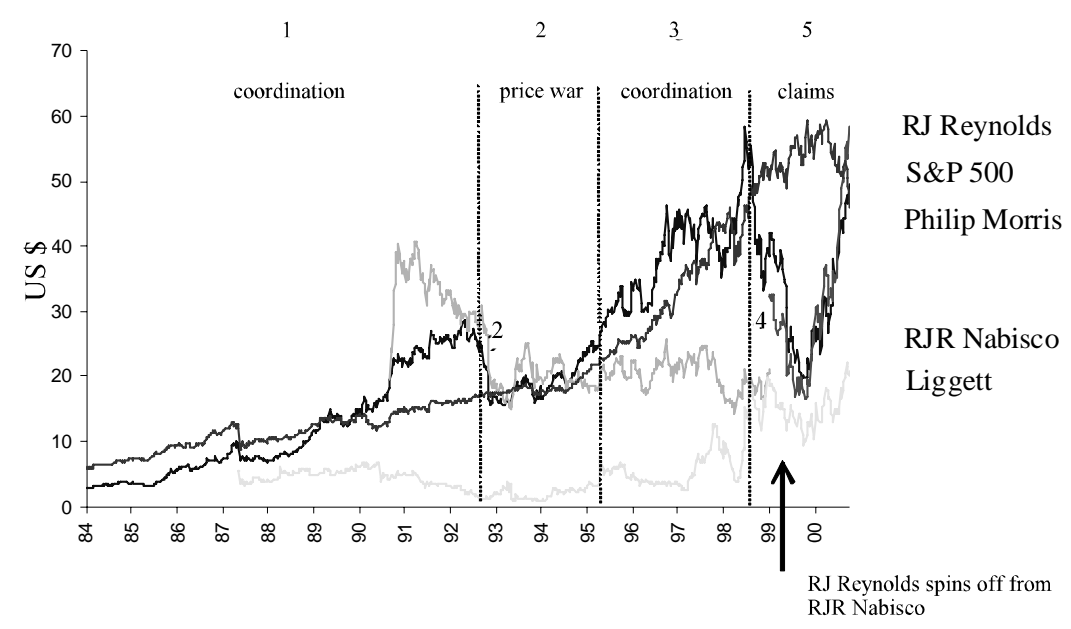

Chronology of events:

(1) Coordination period. Coordination in prices results in superior price performance for the larger cigarette producers compared to the S\&P 500 index and the smaller producers.

(2) A price war in the early 90's due to reciprocating competition results in a general decline in the stock prices of cigarette producers (while the S\&P 500 index shows a steady increase).

(3) Coordination returns. Philip Morris's market value is on the rise.

(4) RJ Reynolds spins off from RJR Nabisco.

(5) Rising legal claims result in a decline in stock prices for the cigarette industry (the S\&P 500 remains stable). 


\section{B. Box Insert Illustration 2: "Learning" to Play the Game in Electronics}

In the late seventies, the introduction of different types of video recorders confirmed that tough positions and reciprocating reactions often result in intensified competition. Philips launched the V2000 system to compete with Sony's Betamax and JVC's VHS system. Instead of following one common product standard, tough positions taken by these companies resulted in an intense market-share battle. This "winner takes all" attitude ultimately proved harmful for the players and turned out to be a "negative-sum game".

In today's competitive landscape, firms may choose to compete on one aspect while cooperating on another at the same time. This was illustrated by the subsequent development of the CD technology a decade later. Philips recognized that the $\mathrm{CD}$ player would be more successful if other firms would also be willing to produce CDs and CD players with a common standard. Philips and Sony exchanged licenses to acquire an install-base for the CD player. The joint development of the CD and the DVD turned out to be a success, resulting in a range of subsequent growth opportunities. It is now apparent that the development of the CD has been a far greater success than initially expected, and the collaboration was beneficial for all players.

Philips had many options associated with the CD technology: an option to wait while doing further research on CD technology, to accelerate or abandon research, to introduce pilot products in a test market, and to start large-scale commercialization. In these cases strategic decisions about technology investment should be based on an expanded view, taking into account the value of the portfolio of embedded options. Beyond this, the analysis must address an additional key aspect: the game-like interaction with competition (Sony). Neglecting this dynamic aspect could have resulted in a disaster, like in the video recorder launch. A proper strategy contingent plan must take into account the interplay between competitors and their joint strategic "moves", just like in a chess game. 